\title{
Zoledronic Acid Inhibits Human Osteoblast Activities
}

\author{
Fernanda G. Basso ${ }^{a}$ Ana Paula Silveira Turrioni ${ }^{b}$ Josimeri Hebling ${ }^{b}$ \\ Carlos A. de Souza Costab \\ a Piracicaba School of Dentistry, UNICAMP - Universidade de Campinas, Piracicaba, and b Araraquara School of \\ Dentistry, UNESP - Universidade Estadual Paulista, Araraquara, Brazil
}

\section{Key Words}

Bisphosphonates · Osteonecrosis · Osteoblasts .

Cytotoxicity

\begin{abstract}
Background: Bisphosphonates are potent inhibitors of bone resorption. These kinds of drugs, which are used for the treatment of osteolytic diseases, have been associated with the occurrence of oral osteonecrosis, especially in patients over 60 years old. Current studies have demonstrated that the cytotoxic effects of bisphosphonates on osteoblasts play an important role in oral osteonecrosis development. Objective: The aim of this study was to evaluate the effect of longterm application of a highly potent bisphosphonate - zoledronic acid (ZA) - on human osteoblasts in vitro. Methods: Human osteoblasts (MG63 cell line) were seeded for $72 \mathrm{~h}$ in wells of 24-well plates. The Dulbecco's modified Eagle's medium (DMEM) was then replaced by culture medium without fetal bovine serum (FBS), and the cells were incubated for an additional $24 \mathrm{~h}$, after which ZA was added to the DMEM without FBS and incubated in contact with osteoblasts for 7, 14 or 21 days. Cell viability (CV), total protein production (TPP), alkaline phosphatase (ALP) activity, mineral nodule formation (MNF), and gene expression of ALP and osteocalcin (OCN), as well as cell morphology by scanning electronic microscopy, were evaluated. Data were statistically analyzed
\end{abstract}

\section{KARGER}

E-Mail karger@karger.com

www.karger.com/ger by Kruskal-Wallis and Mann-Whitney tests, with a significance level of 5\%. Results: The cytotoxic effects of ZA on osteoblasts were characterized by reduction of CV, TPP, ALP and MNF production. In addition, ZA MNF caused a decrease in gene expression of ALP and OCN, as well as intense cell morphology alterations. All these negative effects of ZA were concentration and period dependent. Conclusion: Both concentrations of ZA ( 1 and $5 \mu \mathrm{M}$ ) caused cytotoxic effects to osteoblasts which reduced the production and expression of proteins that play an important role in bone matrix synthesis and mineralization.

(C) 2013 S. Karger AG, Basel

\section{Introduction}

Bisphosphonates are synthetic drugs, derived from pyrophosphate, that have been widely used for the treatment of bone-resorptive diseases [1], which are more incident in patients over 60 years old $[2,3]$. These drugs have also been recommended for adjunctive treatment of bone tumors and bone tumor metastasis $[2,4]$. It is known that bisphosphonates act as bone metabolism regulators, mainly by inhibiting osteoclast activity and apoptosis, which cause decreased bone resorption $[2,4,5]$.

Despite the positive effects of bisphosphonates on osteolytic diseases, these kinds of drugs can also interact 
with other cell types, like osteoblasts, fibroblasts and endothelial cells [6]. It has been reported that bisphosphonates may have cytotoxic effects on such cells, characterized by reductions in cell proliferation and viability, as well as decreased gene expression of growth factors and collagen type I [6-10].

Bisphosphonate-induced osteonecrosis has been described as an adverse side effect observed in patients subjected to long-term bisphosphonate therapy. This is mainly observed with zoledronic acid (ZA), a highly potent bisphosphonate with a high capacity for bone adhesion [11, 12]. In this situation, osteonecrosis may be caused by the intense toxic effects of this kind of drug attached to bone tissue on the surrounding osteoblasts. This negative toxic effect of ZA on bone cells is characterized by reductions in cell viability and gene expression, which, in turn, inhibit local bone healing $[10,13]$. The etiology of osteonecrosis has also been related to the cytotoxic effects of bisphosphonates on oral mucosal adjacent cells, such as fibroblasts and epithelial cells, interfering with local oral mucosal regeneration $[14,15]$.

In fact, the elucidation of the etiopathogenesis of osteonecrosis is crucial, since the incidence of this pathological condition increases with time. Therefore, patients over 60 years old may experience life quality greatly compromised by osteonecrosis. In addition, older patients also frequently show other diseases, such as diabetes mellitus and thrombotic disorders, which can potentiate the risk of osteonecrosis development or even exacerbate this condition [2, 3, 16-19].

In the last few years, several studies have aimed to evaluate the effects of bisphosphonates on different cell types, such as osteoblasts $[20,21]$. In these studies, the authors evaluated at short time intervals the viability, gene expression and mineralization capacity of these cells in an isolated way, which hampers the comparison of results. In addition, some of these studies did not use human cell lines. Therefore, the aim of the present study was to evaluate the effects of ZA applied for different periods on cultured human osteoblasts by assessing their cell viability, morphology, gene expression and mineralization capacity.

\section{Methods}

\section{Cell Culture}

A human osteoblast MG63 cell line (CRL-1427; ATCC, Manassas, Va., USA) was cultured in Dulbecco's modified Eagle's medium (DMEM; GIBCO, Grand Island, N.Y., USA) with 10\% fetal bovine serum (FBS; GIBCO), and $100 \mathrm{IU} / \mathrm{ml}, 100 \mu \mathrm{g} / \mathrm{ml}$ and $2 \mathrm{mM}$ of penicillin, streptomycin and glutamine, respectively (GIBCO).
Table 1. Distribution of groups according to ZA concentrations and evaluation periods (groups 1, 4 and 7 were used as controls for each ZA concentration used and each period of evaluation)

\begin{tabular}{lll}
\hline Group & ZA concentration, $\mu \mathrm{M}$ & Period, days \\
\hline 1 & - & 7 \\
2 & 1 & 7 \\
3 & 5 & 7 \\
4 & - & 14 \\
5 & 1 & 14 \\
6 & 5 & 14 \\
7 & - & 21 \\
8 & 1 & 21 \\
9 & 5 & 21 \\
\hline
\end{tabular}

The cells were incubated with $5 \% \mathrm{CO}_{2}$ at $37^{\circ} \mathrm{C}$ atmosphere (Thermo Plate, Fisher Scientific, Pittsburgh, Pa., USA) [22].

For the experiments, cells were seeded $\left(3 \times 10^{4} \mathrm{cells} / \mathrm{cm}^{2}\right)$ in wells of 24 -well plates in complete DMEM containing $\beta$-glycerol phosphate and ascorbic acid (Sigma-Aldrich, St. Louis, Mo., USA). After a 72-hour incubation period, the complete DMEM was replaced by new DMEM without FBS, and the cells were incubated for an additional $24 \mathrm{~h}$. Then, two different concentrations of ZA (1 and $5 \mu \mathrm{M}$ ) were added to DMEM without FBS (table 1) and the cells were incubated in contact with these ZA solutions for 7, 14 or 21 days. During these periods, the ZA solutions were replaced every $72 \mathrm{~h}$. Finally, the osteoblasts were evaluated for cell viability (CV), total protein production (TPP), alkaline phosphatase (ALP) activity, mineral nodule formation $(\mathrm{MNF})$, and gene expression of $\mathrm{AP}$ and osteocalcin (OCN), as well as cell morphology (scanning electronic microscopy), as described below.

\section{Cell Viability: MTT Assay}

Cell viability was determined by MTT assay, which evaluates the respiratory activity of viable cells $[22,23]$. For this assay, a $900-\mu l$ quantity of DMEM without FBS and a 100- $\mu$ l quantity of MTT solution ( $5 \mathrm{mg} / \mathrm{ml}$ of MTT salt; Sigma-Aldrich) were added to the samples $(n=8)$ and incubated for $4 \mathrm{~h}$. Then, the MTT solution was aspirated and the formazan crystals were dissolved with $600 \mathrm{nl}$ of acidified isopropanol $(0.04 \mathrm{~N}$ of $\mathrm{HCl})$. Cell viability was determined by absorbance of the purple solution obtained from crystal dissolution in a spectrophotometer at $570 \mathrm{~nm}$ (Thermo Plate, Nanshan District, Shenzhen, China). The protocol was performed in triplicate.

\section{Total Protein Production}

TPP was evaluated as previously described [22]. After ZA treatment for experimental periods, cells underwent lysis with $0.1 \%$ sodium lauryl sulfate (Sigma-Aldrich) for $40 \mathrm{~min}$. Lowry Solution (Sigma-Aldrich) was then added to each sample $(\mathrm{n}=8)$ for $20 \mathrm{~min}$, followed by Folin and Ciocalteau's Phenol Reagent (Sigma-Aldrich). After $30 \mathrm{~min}$, the samples were aliquoted and protein production was determined by the solutions' absorbance at $655 \mathrm{~nm}$ (Thermo Plate) [22]. Protein concentration was obtained based on a standard curve with known protein concentrations. The protocol was performed in triplicate. The TPP results from each sample were used in order to normalize ALP activity results. 


\section{ALP Activity}

ALP activity was assessed $(n=8)$ according to an end-point kit protocol (Labtest Diagnóstico S.A., Lagoa Santa, Brazil) [24]. This assay is based on dephosphorylation of thymolphthalein by ALP.

ALP was determined based on the solution's absorbance at 590 nm (Thermo Plate). For this test, a standard curve with known concentrations of ALP was used to determine ALP activity. The protocol was performed in triplicate.

\section{Mineral Nodule Formation}

The formation of mineral nodules characterizes the mineralization capability of osteoblasts [21]. For this evaluation, Alizarin Red stain was used, as described below.

Cells were fixed in $70 \%$ ethanol for $1 \mathrm{~h}$, after which Alizarin Red solution (40 nm; pH 4.2; Sigma-Aldrich) was added to the samples $(\mathrm{n}=8)$ for $20 \mathrm{~min}$ with shaking. The samples were washed twice with distilled water. For quantitative analysis by absorbance evaluation, nodules were solubilized with $10 \%$ cetylpyridinium chloride (Sigma-Aldrich) for $15 \mathrm{~min}$ with shaking. Absorbance was determined at $562 \mathrm{~nm}$ (Thermo Plate).

MNF of each group was determined by means of a light microscope (Olympus BX51; Olympus, Miami, USA) equipped with a digital camera (Olympus C5060; Olympus). The protocol was performed in triplicate.

\section{Gene Expression of ALP and OCN}

To complement the data on mineralization capacity of cultured osteoblasts after treatment with ZA for 7-, 14- and 21-day periods, gene expression of ALP and OCN was evaluated by real-time PCR. These genes are considered osteoblast and mineralization markers [25]. In this protocol, RNA extraction and cDNA synthesis were performed as previously described [22]. RNA isolation was performed by Trizol method, according to the manufactures' instructions. The RNA concentration was evaluated by means of a Biophotometer (Eppendorf, Hamburg, Germany) at a proportion of 1:49. Analysis of the RNA concentration was used to standardize the amount of RNA of each sample for cDNA synthesis. The cDNA was obtained with the use of the High Capacity cDNA Reverse Transcriptions Kit (Applied Biosystems, Foster City, Calif., USA), following the recommended protocol $\left[25^{\circ} \mathrm{C}(10 \mathrm{~min}), 37^{\circ} \mathrm{C}(120\right.$ $\min ), 85^{\circ} \mathrm{C}(5 \mathrm{~s}), 4^{\circ} \mathrm{C}$.

Gene expression was evaluated by real-time PCR (qPCR) [22]. Specific primer sets were used for each selected gene (table 2). The reactions were prepared with standardized qPCR reagents $\left(\mathrm{SYBR}^{\circledR}\right.$ Green PCR Master Mix; Applied Biosystems) associated with the primer sets for each gene. Fluorescence was determined by Step One Plus (Applied Biosystems) at each amplification cycle and analyzed by Step One Software 2.1 (Applied Biosystems). All reactions were subjected to the same conditions and normalized by ROX fluorescence to reduce artifacts caused by sample evaporation and volume differences. The results were obtained as CT values representing the numbers of amplification cycles needed to achieve detection for each sample. These results were grouped by ZA concentrations and periods of treatment, and normalized by an endogenous control gene (RPL13). The protocol was performed in triplicate.

\section{Cell Morphology Analysis}

Cell morphology was evaluated by scanning electron microscopy as in previous studies [22, 24, 26]. Sterilized round glasses (13 $\mathrm{mm}$ in diameter) were individually placed at the bottoms of wells
Table 2. Primer sequences of each selected gene

\begin{tabular}{ll}
\hline Gene & Sequence \\
\hline ALP & $\begin{array}{l}\text { Forward: 5'-GACAAGAAGCCCTTCACTGC-3' } \\
\text { Reverse: } 5^{\prime} \text {-AGACTGCGCCTGGTAGTTGT-3' }\end{array}$ \\
\hline OCN & $\begin{array}{l}\text { Forward: 5'-GGCGCTACCTGTATCAATGG-3' } \\
\text { Reverse: } 5^{\prime} \text {-TCAGCCAACTCGTCACAGTC-3' }\end{array}$ \\
\hline RPL13 & Forward: 5'-CCGCTCTGGACCGTCTCAA-3' \\
& Reverse: $5^{\prime}$-CCTGGTACTTCCAGCCAACCT-3' \\
\hline
\end{tabular}

of 24-well plates. The cells were then seeded and treated as described above $(\mathrm{n}=2)$. After 7, 14 and 21 days, the ZA solutions were aspirated and the cells attached to the round glass substrate were rinsed with phosphate buffer. The cells were then fixed with $2.5 \%$ glutaraldehyde solution (Sigma-Aldrich) for $1 \mathrm{~h}$ at room temperature and postfixed with $1 \%$ osmium tetroxide for $1 \mathrm{~h}$. After that, cells were treated with different concentrations of ethanol for 30 min each (30, 50 and 70\%). The cells were maintained in 95 and $100 \%$ ethanol solutions for $60 \mathrm{~min}$ each and then treated for $20 \mathrm{~min}$ with $200 \mu \mathrm{l}$ of 1,1,1,3,3,3 hexamethyldisilazane (HMDS; SigmaAldrich; 3 times).

The round glasses containing cells were removed from the wells, set on metallic stubs and maintained in a desiccator overnight. Before analysis, the samples were covered with gold and analyzed by scanning electronic microscopy (JEOL-JMS-T33A Scanning Electron Microscope, JEOL USA Inc., Peabody, Mass., USA).

\section{Statistical Analysis}

CV, TPP, MNF and qPCR data were analyzed by Kruskal-Wallis tests complemented by Mann-Whitney tests for comparison of different concentrations of ZA and different treatment periods. Statistical significance was set at $5 \%$.

\section{Results}

\section{Cell Viability: MTT Assay}

The results of cell viability evaluation by MTT assay of osteoblasts treated with ZA for 7, 14 and 21 days showed that at 7 days both concentrations of ZA significantly decreased cell viability compared to that in the control group ( $\mathrm{p}<0.05$; fig. 1 ). No difference in cell viability in the control groups at 7 and 14 days was observed ( $p>$ $0.05)$. In the 21-day control group, a significant increase of cell viability was observed compared to that in the 7 and 14-day periods $(\mathrm{p}<0.05)$.

Both concentrations of ZA ( 1 and $5 \mu \mathrm{M}$ ) decreased cell viability at the 7 - and 14-day periods in a concentrationdependent manner. At the 21-day period, both ZA concentrations caused an intense decrease in cell viability $(\mathrm{p}>0.05)$. 


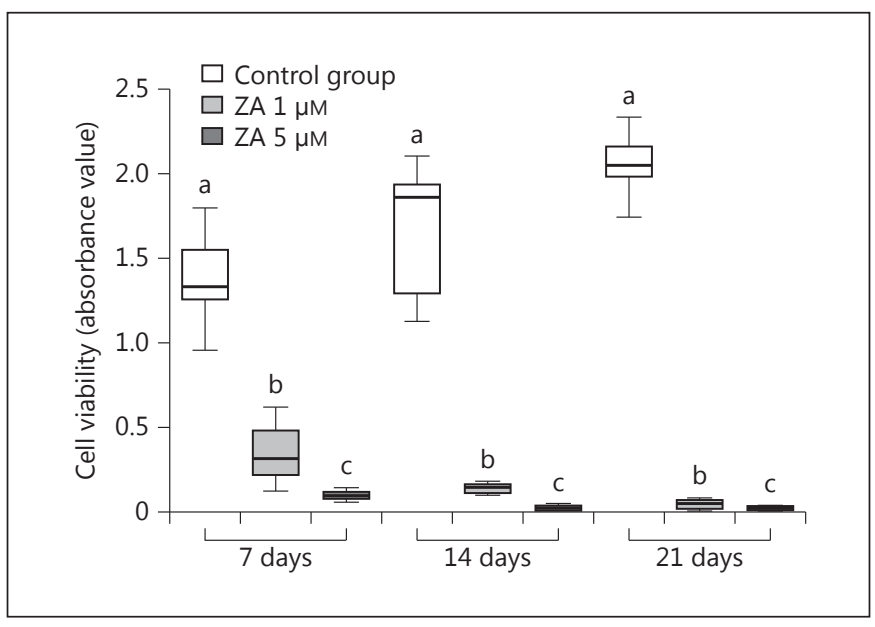

Fig. 1. Cell viability of culture human dosteoblasts (MG63) treated with ZA at 1 and $5 \mu \mathrm{M}$ for 7,14 and 21 days. Letters allow comparison among groups within each period of evaluation. Groups represented by the same letter are not statistically different (MannWhitney, $\mathrm{p}>0.05$ ).

Both ZA concentrations reduced cell viability in a period-dependent manner. For the 1- $\mu \mathrm{M} \mathrm{ZA}$ solution, no statistical difference between the 7- and 14-day periods was observed ( $p>0.05)$. However, for the 5- $\mu \mathrm{M}$ ZA solution, the cell viability reduction was significant for all treatment periods $(\mathrm{p}<0.05)$. No difference was observed between the 14- and 21-day periods ( $\mathrm{p}>0.05$ ). Besides cell viability, other cell functions were compromised by prolonged ZA treatment.

\section{Total Protein Production}

The TPP was evaluated by a Lowry's modified method and demonstrated the total amount of protein production by osteoblasts treated with ZA for the different periods proposed. Regarding the control group, the TPP was only increased at 21 days after cell culture compared to that at the 7 - and 14 -day periods $(\mathrm{p}<0.05)$. When the cells were treated with $1 \mu \mathrm{MZA}$ solution, a significant decrease in TPP occurred only after 21 days of treatment, compared to that after the 7- and 14-day periods ( $p<0.05$; fig. 2). Results of TPP were also used to normalize ALP activity data of cultured osteoblasts treated with ZA.

\section{ALP Activity}

ALP is an enzyme strictly related to matrix mineralization and the activity of this enzyme was evaluated by an end-point assay. Results showed that an increased ALP activity was observed only when the osteoblasts were

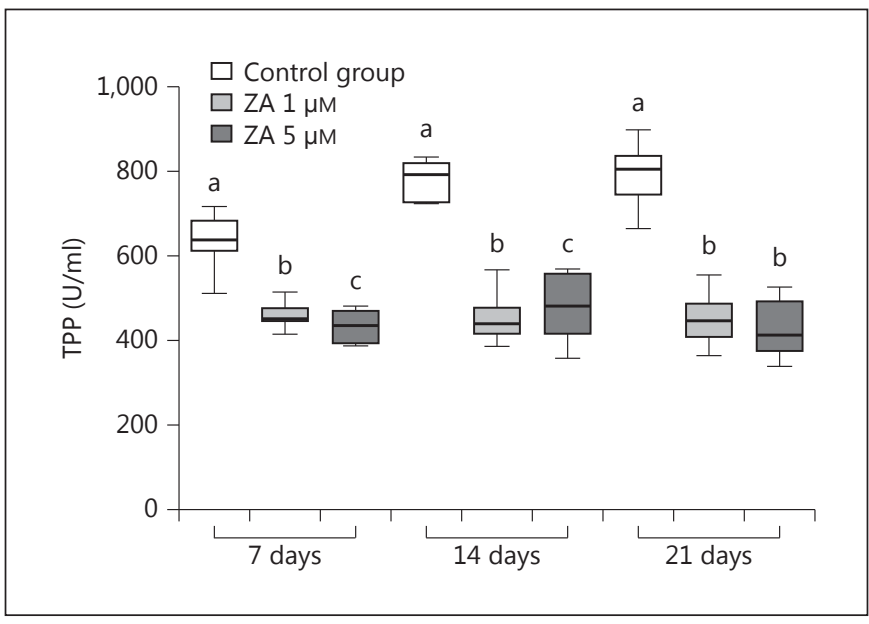

Fig. 2. TPP by cultured human osteoblasts (MG63) treated with $\mathrm{ZA}$ at 1 and $5 \mu \mathrm{M}$ for 7, 14 and 21 days. Letters allow comparison among groups within each period of evaluation. Groups represented by the same letter are not statistically different (MannWhitney, $\mathrm{p}>0.05$ ).

treated for 7 days with $5 \mu \mathrm{M}$ ZA solution $(\mathrm{p}<0.05)$. At 14 days, both ZA concentrations ( 1 and $5 \mu \mathrm{M}$ ) significantly decreased the ALP activity compared to the control group $(\mathrm{p}<0.05)$. At the 21-day period, no difference was found in ALP when the experimental and control groups were compared $(\mathrm{p}>0.05)$.

Considering both ZA concentrations used in this study, no difference was observed when osteoblasts were treated with only $1 \mu \mathrm{M}$ of $\mathrm{ZA}$ in all experimental periods $(\mathrm{p}>0.05)$. However, treatment with $5 \mu \mathrm{M}$ of $\mathrm{ZA}$ solution caused significant ALP reduction at the 14- and 21-day periods (fig. 3).

\section{Mineral Nodule Formation}

The mineralization capacity of cultured osteoblasts treated with ZA was also evaluated by mineral nodules formation, by Alizarin Red assay. In general, the MNF observed in this study was concentration and time dependent. In control groups, a significant MNF increase occurred with time. In those groups in which the cells were exposed to ZA, a decrease of MNF was observed compared to that in the control groups $(\mathrm{p}<0.05)$. However, independent of the ZA concentration applied to the cells, the increase of nodule formation was directly related to the periods of treatment (fig. 4,5).

Mineralization capacity and differentiation of osteoblasts were confirmed by evaluation of gene expression of ALP and OCN. 


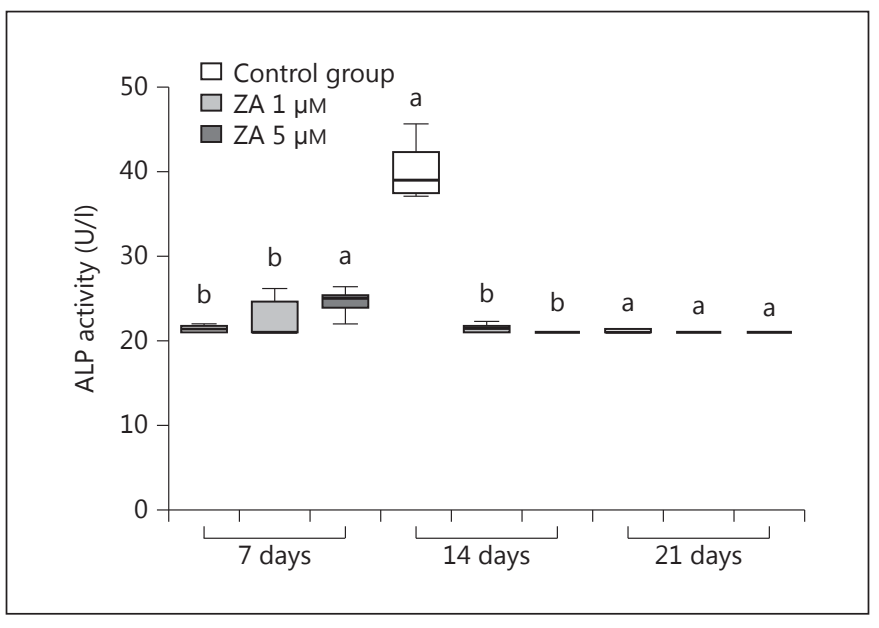

Fig. 3. ALP activity of osteoblasts (MG63) treated with ZA at 1 and $5 \mu \mathrm{M}$ for 7,14 and 21 days. Letters allow comparison among groups within each period of evaluation. Groups represented by the same letter are not statistically different (Mann-Whitney, $\mathrm{p}>0.05$ ).

\section{Gene Expression of ALP and OCN}

Gene expression determined by real-time PCR demonstrated no different $\mathrm{OCN}$ expression for control groups at different periods $(\mathrm{p}>0.05)$. Independent of the ZA concentration used in this study ( 1 or $5 \mu \mathrm{M})$, a significant decrease in OCN expression occurred at the 21-day period (fig. 6).

Decreased ALP gene expression was observed at the 7-day period (for the 5- $\mu \mathrm{M} \mathrm{ZA}$ solution) and the 14-day period (for the 1- $\mu \mathrm{M} Z \mathrm{ZA}$ solution), which was concentration dependent. At the 21-day period, ALP expression was almost none for both ZA concentrations evaluated, with no statistically significant difference between them ( $p>0.05$; fig. 7 ).

\section{Cell Morphology Analysis}

The evaluation of cell morphology by scanning electron microscopy is a qualitative analysis that allowed the observation of cultured osteoblasts after prolonged treatment with ZA. Culture of human osteoblasts exposed to $\mathrm{ZA}$ at $1-$ and 5- $\mu \mathrm{M}$ solutions caused intense alterations in the morphology of those cells that remained attached to the glass substrate. It was also observed that a number of cells lethally affected by the ZA added to the culture medium detached from the substrate. At 14- and 21-day periods of cell exposure to ZA solutions, the alterations in cell morphology were more evident than those observed at 7 days. In addition, more dead cells detached

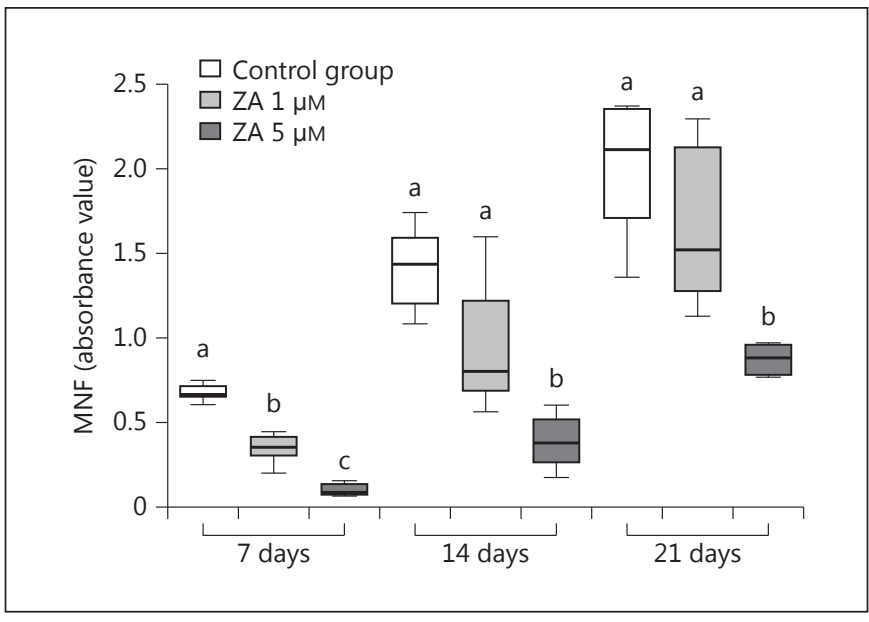

Fig. 4. MNF (Alizarin Red stain) by cultured human osteoblasts (MG63) treated with ZA at 1 and $5 \mu \mathrm{M}$ for 7, 14 and 21 days. Letters allow comparison among groups within each period of evaluation. Groups represented by the same letter are not statistically different (Mann-Whitney, $\mathrm{p}>0.05$ ).

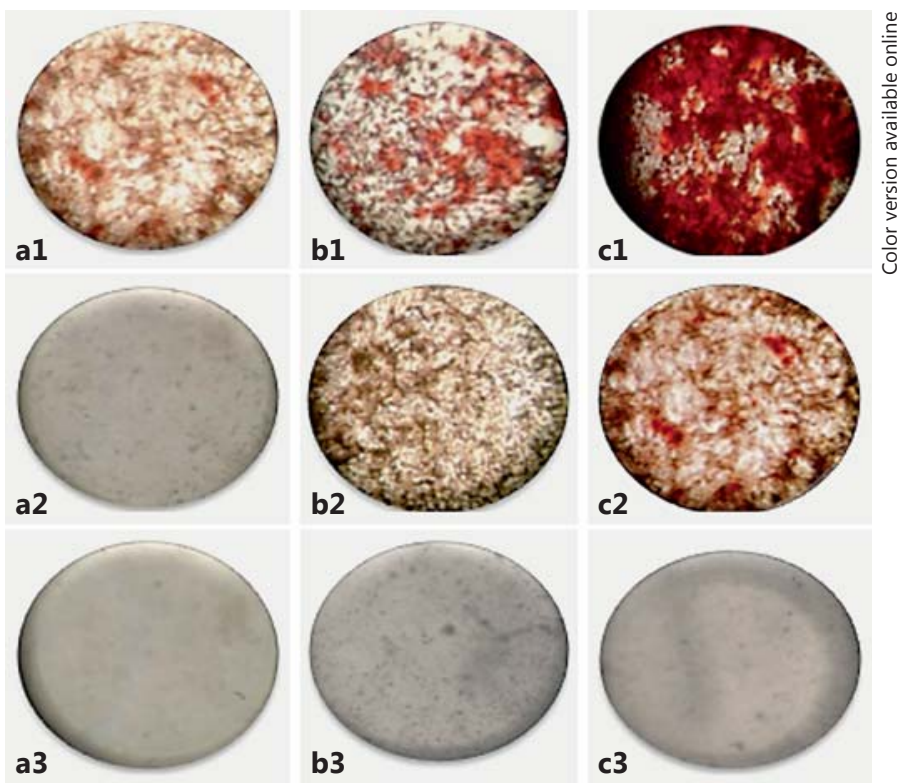

Fig. 5. General view of in vitro MNF after treatment of osteoblasts with ZA at different concentrations ( 1 and $5 \mu \mathrm{M})$ for 7,14 and 21 days. 7 days (a); 14 days (b); 21 days (c): control group (1); ZA $1 \mu \mathrm{M}(2)$; ZA $5 \mu \mathrm{M}$ (3).

from the substrate, which exhibited greater cell-free areas. In control groups, numerous osteoblasts with normal morphology were attached to the glass substrate (fig. 8). 


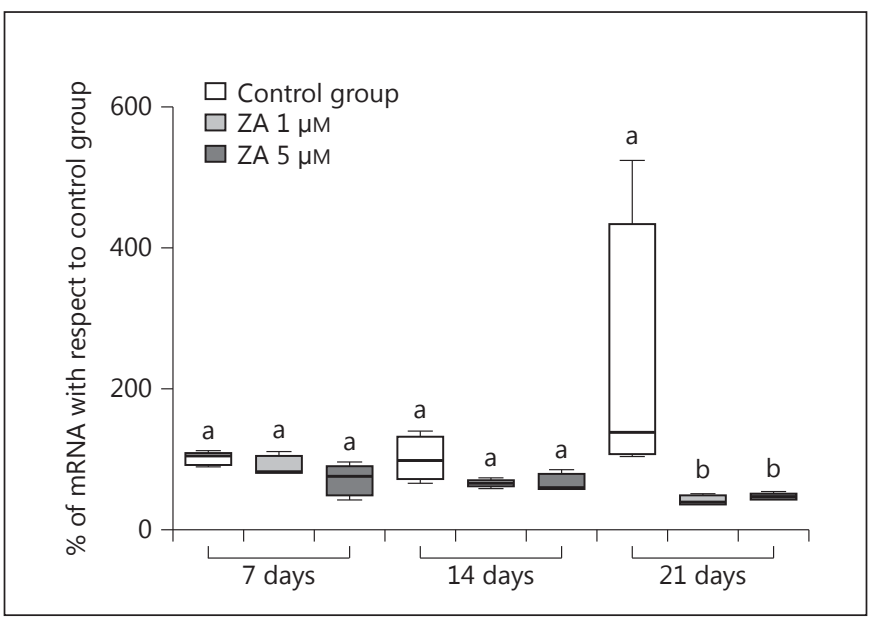

Fig. 6. OCN gene expression by real-time PCR by osteoblasts (MG63) treated with ZA at different concentrations ( 1 and $5 \mu \mathrm{M})$ for 7, 14 and 21 days. Letters allow comparison among groups within each period of evaluation. Groups represented by the same letter are not statistically different (Mann-Whitney, $\mathrm{p}>0.05$ ).

\section{Discussion}

Therapies with bisphosphonates have been related to the occurrence of oral osteonecrosis, which is frequently found in patients over 60 years old. This fact can be associated with the increased prescription of these kinds of drugs to this group of patients, or even with other local and systemic factors that have already been related to the osteonecrosis etiopathogenesis, such as administration of drugs that: (1) inhibit local vascularization [27], (2) increase bone loss and impair bone remodeling [28, 29], and (3) increase local bacterial colonization [30], even in clinical situations in which there is local persistent trauma caused by a removable dental prosthesis [31].

Recent studies have shown that the etiopathogenesis of this condition is more frequent in patients under nitrogen-containing bisphosphonate, which present a higher potency, due to the increased capacity of adhesion to mineral tissues $[11,12]$. Therefore, the authors selected ZA for this study, considering that ZA is the most potent of all nitrogen-containing bisphosphonates and has been highly related to osteonecrosis development. Considering the bisphosphonates-treated bone diseases, this study also considered the cancer patients under bisphosphonate treatment, for whom, in most cases, ZA is prescribed [1].

Several studies have evaluated the effects of bisphosphonates, including ZA, on cell cultures $[6,8,9]$. Several authors have demonstrated that the cytotoxicity of ZA plays an important role in the development of osteone-

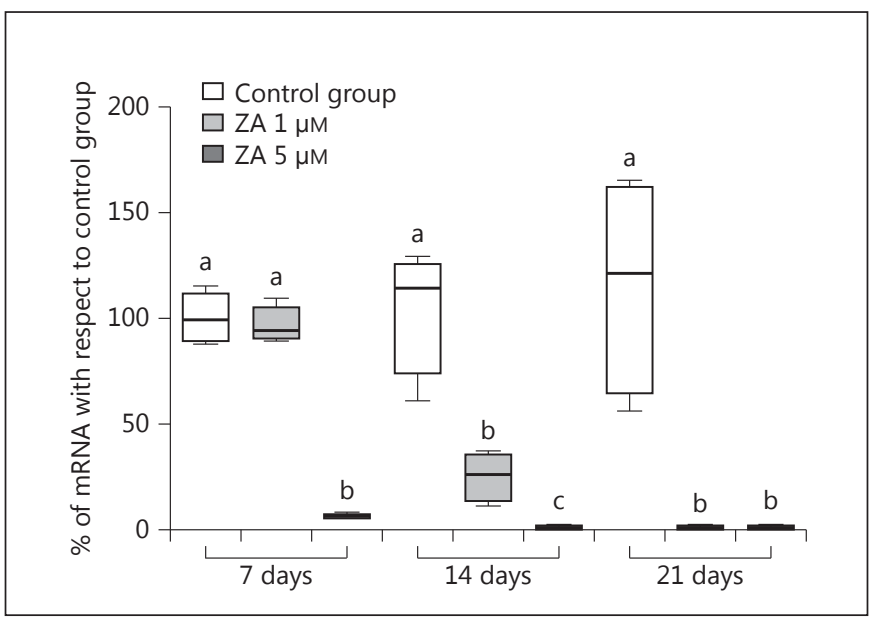

Fig. 7. ALP gene expression by real-time PCR by osteoblasts (MG63) treated with ZA at different concentrations ( 1 and $5 \mu \mathrm{M})$ for 7, 14 and 21 days. Letters allow comparison among groups within each period of evaluation. Groups represented by the same letter are not statistically different (Mann-Whitney, $\mathrm{p}>0.05$ ).
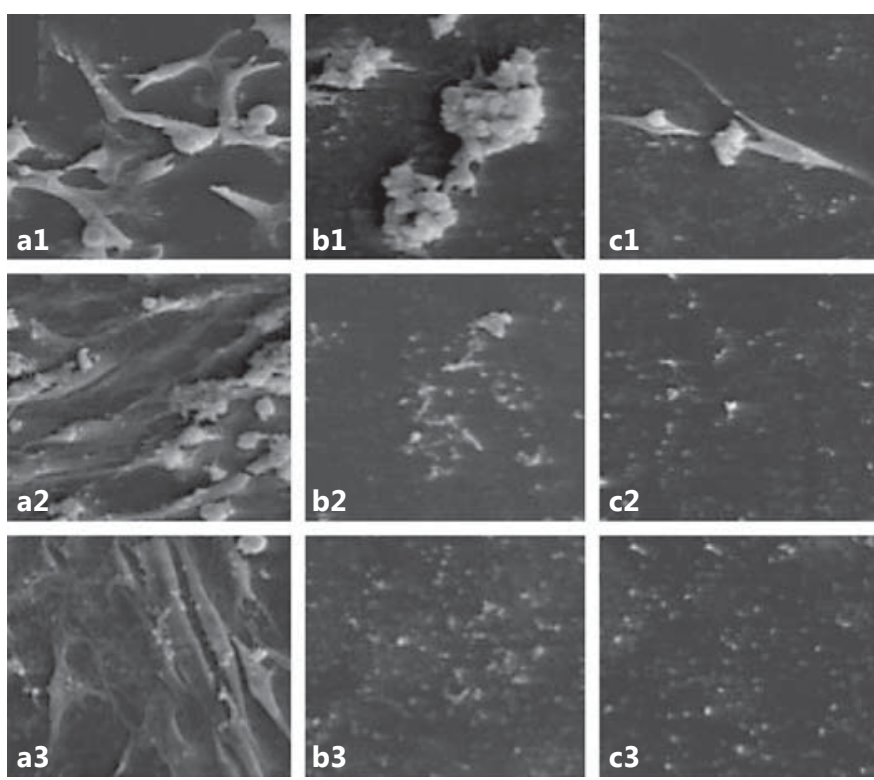

$\overline{20 \mu \mathrm{M}}$

Fig. 8. Scanning electronic microscopy images obtained from the glass substrate on which the osteoblasts (MG63) were seeded. In control groups (a1-3), numerous osteoblasts with normal morphology can be observed attached to the substrate (7-, 14- and 21day periods, respectively). In ZA-treated groups at $1 \mu \mathrm{M}(\mathbf{b} 1-3)$ and $5 \mu \mathrm{M}(\mathbf{c} 1-3)$, reduced numbers of osteoblasts $(\mathbf{b} 1, \mathbf{c} 1)$ or even lack of cells on the glass substrate $(\mathbf{b} 2,3, \mathbf{c} 2,3)$ are observed. Residual cytoplasm membrane of dead cells that detached from the substrate can be seen in $\mathbf{b} 2,3$ and $\mathbf{c} 2,3$. Original magnification $\times 500$. 
crosis, which is a secondary negative side effect caused by bisphosphonate treatment $[8,14]$.

Previous studies showed the effects of ZA treatment on different cell types, including osteoblasts $[6,32]$. However, these studies evaluated ZA treatment for short periods, considering the IV infusion contact period (IV distribution). The present study, on the other hand, evaluated the effects of ZA for long contact periods on cultured osteoblasts. This was performed due to the fact that alveolar bone is in constant remodeling process, which, in turn, causes a continuous release of ZA from bone tissue, maintaining the contact of this drug to the local cells for a long time.

In the present in vitro study, 1- and 5- $\mathrm{MM} \mathrm{ZA}$ concentrations were used based upon a prior investigation in which Scheper et al. [8] evaluated the concentrations of ZA found in saliva and bone tissue of patients subjected to therapy with this highly potent bisphosphonate. The authors determined that ZA concentrations in saliva and bone varied from 0.7 to $4.6 \mu \mathrm{M}$. In addition, the ZA concentrations detected after drug infusion varied from 0.4 to $5 \mu \mathrm{M}$. In the present study, it was shown that both ZA concentrations tested $(1$ and $5 \mu \mathrm{M})$ significantly decreased the metabolism of cultured human osteoblasts. This cell viability reduction, observed at the 7-day period, was maintained 14 and 21 days after cell exposure to ZA. The absence of differences in cell viability between the 14- and 21-day periods may be explained by the intense cytotoxic effect of ZA at $5 \mu \mathrm{M}$, which was confirmed by scanning electronic microscopy. Previous studies also demonstrated the toxic effects of this kind of bisphosphonate on different cell types, even after shorter periods of treatment $[8,9]$. However, the aim of this study was to determine the cytotoxicity of ZA on osteoblasts after long-term treatment and also to evaluate the mineralization potential of these cells after being exposed to 1 and $5 \mu \mathrm{M}$ ZA concentrations, which can be clinically found in saliva and bone. Therefore, as demonstrated by Idris et al. [20], it was observed in the present study that bisphosphonates over $1 \mu \mathrm{M}$ can promote the inhibition of osteoblast growth in vitro. Idris et al. [20] reported that bisphosphonates increased osteoblast apoptosis in a concentration-related manner. Despite the fact that cell death was not evaluated in the present study, it was possible, showing that ZA cytotoxicity intensity was also concentration dependent.

According to Ziebart et al. [33], the decrease of cell viability observed when cells are treated with ZA could be associated to the reduction of geranylgeraniol expression, which plays a role in the intracellular protein functions, being directly related to cell viability and migration.
Evaluating the therapeutic and over-therapeutic doses of bisphosphonates on osteoblasts, Naidu et al. [32] demonstrated that these kinds of drugs are capable of reducing viability and protein expression by osteoblasts in culture. In addition, Orris et al. [21] reported that osteoblasts exposed for 14 days to ZA at 10 and $100 \mathrm{nM}$, and 1 and $10 \mu \mathrm{M}$ decreased the numbers of viable cells by $20,30,40$ and $90 \%$, respectively. These results were further corroborated by Walter et al. [6], who evaluated the negative side effects caused by ZA on cultured endothelial cells, fibroblasts and osteoblasts. In contrast, Im et al. [25] showed that low concentrations of bisphosphonates, such as $10^{-4} \mathrm{M}$ and $10^{-12} \mathrm{M}$, can increase osteoblast proliferation. However, the bisphosphonate concentrations used by Im et al. [25] were significantly lower than those determined in serum levels, saliva, or even bone tissue of patients subjected to therapy with these kinds of drugs [8]. Consequently, analysis of the data presented in this in vitro study, as well as those shown in previous investigations, confirms that the negative side effects caused by bisphosphonates, such as ZA, depend on both the length of therapy and the concentration of the drug.

In the present study, osteoblasts exposed for 7 days to ZA solution at $5 \mu \mathrm{M}$ also exhibited ALP activity reduction. Similar data, which were also observed in a previous study [20], reflect the osteogenic differentiation of cultured osteoblasts, despite the environmental conditions available. However, intense ALP reduction occurs with time (14and 21-day periods), indicating that specific concentrations of ZA can inhibit osteoblast differentiation and its mineralization capacity, as previously demonstrated $[9$, $20,21]$. In addition, it was shown in the present study that both ZA concentrations ( 1 and $5 \mu \mathrm{M}$ ) inhibited MNF in a concentration-dependent manner. In control groups, the osteoblasts that were not exposed to ZA presented an increase in MNF over time, which corroborated the results of previous studies [20,21].

As in this study, Simon et al. [9] demonstrated a reduction in Col-I expression by osteoblasts exposed to ZA at different concentrations. Regarding ALP and OCN expression relative to matrix mineralization, $\mathrm{Im}$ et al. [25] also observed that ZA treatment for 7, 14 and 21 days caused decreased expression of these genes. The decreased gene expression of these three proteins may impair bone formation and remodeling $[9,25]$. All these negative side effects of ZA on osteoblast activities may be clinically related to the development and evolution of osteonecrosis, affecting the life-quality of patients under bisphosphonate therapy. 


\section{Conclusions}

According to the protocols used in this in vitro study, it can be concluded that ZA caused cytotoxic effects on cultured human osteoblasts in a dose-dependent manner and a decrease of the mineralization capacity of these cells, which are directly involved in bone matrix synthesis and mineralization processes.

\section{Acknowledgements}

The authors acknowledge the Fundação de Amparo à Pesquisa do Estado de São Paulo - FAPESP (grants: 2009/54722-1 and BP.DR: 2009/52326-1) and the Conselho Nacional de Desenvolvimento Científico e Tecnológico - CNPq (grant: 301291/2010-1) for financial support.

\section{References}

1 Body JJ, Mancini I: Bisphosphonates for cancer patients: why, how and when? Support Care Cancer 2002;10:399-407.

-2 Migliorati CA, Casiglia J, Epstein J, Jacobsen PL, Siegel MA, Woo S: Managing the care of patients with bisphosphonate-associated osteonecrosis. JADA 2005;136:1658-1668.

3 Benhamou C: Effects of osteoporosis medications in bone quality. Joint Bone Spine 2007; 74:39-47.

4 Diel IJ, Fogelman I, Al-Nawas B, Hoffmeister B, Migliorati C, Gligorov J, Väänänen K, Pylkkänen L, Pecherstorfer M, Aapro MS: Pathophysiology, risk factors and management of bisphosphonate-associated osteonecrosis of the jaw: is there a diverse relationship of amino and non-aminobisphosphonates? Crit Rev Oncol Hematol 2007;64:198-207.

5 Woo S, Hellstein JW, Kalmar JR: Systematic review: bisphosphonates and osteonecrosis of the jaws. Ann Intern Med 2006;144:753-761.

-6 Walter C, Klein MO, Pabst A, Al-Nawas B, Duschner H, Ziebart T: Influence of bisphosphonates on endothelial cells, fibroblasts, and osteogenic cells. Clin Oral Investig 2010;14: $35-41$.

7 Scavelli C, Di Pietro G, Cirulli T, Cluccia M, Boccarelli A, Giannini T, Mangialardi T, Bertieri R, Coluccia AML, Ribatti D, Dammacco F, Vacca A: Zoledronic acid affects over-angiogenic phenotype of endothelial cells in patients with multiple myeloma. Mol Cancer Ther 2007;6:3256-3262.

$\checkmark 8$ Scheper MA, Badros A, Salama AR, Warburton G, Cullen KJ, Weikel DS, Meiller TF: A novel bioassay model to determine clinically significant bisphosphonate levels. Support Care Cancer 2009;17:1553-1557.

-9 Simon MJK, Niehoff P, Kimming B, Wiltfang J, Açil Y: Expression profile and synthesis of different collagen types I, II, III and V of human gingival fibroblasts, osteoblasts, and SaOs-2 cells after bisphosphonate treatment. Clin Oral Investig 2010;14:51-58.

10 Koch FP, Yekta SS, Merkel C, Ziebart T, Smeets R: The impact of bisphosphonates on the osteoblast proliferation and collagen gene expression in vitro. Head Face Med 2010;6: $12-17$.
11 Lawson MA, Xia Z, Barnett BL, Triffitt JT, Phipps RJ, Dunford JE, Locklin RM, Ebetino FH, Russell RGG: Differences between bisphosphonates in binding affinities for hydroxyapatite. J Biomed Mater Res B Appl Biomater 2010;92:149-155.

12 Otto S, Pautke C, Opelz C, Westphal I, Drosse I, Schwager J, Bauss F, Ehrenfeld M, Scheker M: Osteonecrosis of the jaw: effect of bisphosphonate type, local concentration, and acidic milieu on the pathomechanism. J Oral Maxillofac Surg 2010;68:2837-2845.

13 Pozzi S, Vallet S, Mukherjee S, Cistea D, Vaghela N, Santo L, Rosen E, Ikeda H, Okawa Y, Kiziltepe T, Schoonmaker J, Xie W, Hideshima T, Weller E, Bouxsein ML, Munshi NC, Anderson KC, Raje N: High-dose zoledronic acid impacts bone remodeling with effects on osteoblastic lineage and bone mechanical properties. Clin Cancer Res 2009;15:5829-5839.

14 Reid IR, Bolland MJ: Is bisphosphonate-associated osteonecrosis of the jaw caused by soft tissue toxicity? Bone 2007;41:318-320.

15 Reid IR: Osteonecrosis of the jaw - who gets it and why? Bone 2009;44:4-10.

16 Badros A, Weikel D, Salama A, Goloubeva O, Schneider A, Rapoport A, Fenton R, Gahres N, Sausville E, Ord R, Meiller T: Osteonecrosis of the jaw in multiple myeloma patients: clinical features and risk factors. J Clin Oncol 2006;24:945-952.

17 Wutzl A, Eisenmenger G, Hoffmann M, Czerny C, Moser D, Pietschmann P, Ewers R, Baumann A: Osteonecrosis of the jaws and bisphosphonate treatment in cancer patients. Wien Klin Wochenschr 2006;118:473-478.

18 Zavras AI, Zhu S: Bisphosphonates are associated with increased risk for jaw surgery in medical claims data: is it osteonecrosis? J Oral Maxillofac Surg 2006;64:917-923.

19 Scoletta M, Arduino PG, Reggio L, Dalmasso P, Mozatti M: Effect of low-level laser irradiation on bisphosphonate-induced osteonecrosis of the jaws: preliminary results of a prospective study. Photomed Laser Surg 2010;28: 179-184.

20 Idris A, Rojas J, Greig IR, Van't Hof RJ, Ralston SH: Aminobisphosphonates cause osteoblast apoptosis and inhibit bone nodule formation in vitro. Calcif Tissue Int 2008;82: 191-201.
21 Orris IR, Key ML, Colston KW, Arnett TR: Inhibition of osteoblast function in vitro by aminobisphosphonates. J Cell Biochem 2008; 106:109-118

-22 Basso FG, Oliveira CF, Kurachi C, Hebling J, Costa CA: Biostimulatory effect of low-level laser therapy on keratinocytes in vitro. Lasers Med Sci 2012, Epub ahead of print.

23 Mosmann T: Rapid colorimetric assay for cellular growth and survival: application to proliferation and cytotoxicity assays. J Immunol Methods 1983;65:55-63.

24 Oliveira CF, Basso FG, Lins EC, Kurachi C, Hebling J, Bagnato VS, de Souza Costa CA: Increased viability of odontoblast-like cells subjected to low-level laser irradiation. Laser Physics 2010;20:1659-1666.

-25 Im G, Qureshi SA, Kenney J, Rubash HE Shanbhag AS: Osteoblast proliferation and maturation by bisphosphonates. Biomaterials 2004;25:4105-4115.

26 Oliveira CF, Basso FG, Lins EC, Kurachi C, Hebling J, Bagnato VS, de Souza Costa CA: In vitro effect of low-level laser on odontoblastic-like cells. Laser Phys Lett 2011;8:155-163.

27 Aaron KR, Voisinet A, Racine J, Ali Y, Feller ER: Corticosteroid-associated avascular necrosis: dose relationships and early diagnosis. Ann NY Acad Sci 2011;1240:38-46.

28 Clarke BL, Khosla S: Physiology of bone loss. Radiol Clin North Am 2010;48:483-495.

29 Marie PJ, Kassem M: Extrinsic mechanisms involved in age-related defective bone formation. J Clin Endocrinol Metab 2011;96:600-609.

30 Ogawa H, Yoshihara A, Hirotomi T, Ando Y, Miyazaki H: Risk factors for periodontal disease progression among elderly people. J Clin Periodontol 2002;29:592-597.

31 Gendreau L, Loewy ZG: Epidemiology and etiology of denture stomatitis. J Prosthodont 2011;20:251-260.

32 Naidu A, Dechow PC, Spears R, Wright JM, Kessler HP, Opperman LA: The effects of bisphosphonates on osteoblasts in vitro. Oral Surg Oral Med Oral Pathol Oral Radiol Endod 2008;106:5-13.

33 Ziebart T, Koch F, Klein MO, Guth J, Adler J, Pabst A, Al-Nawas B, Walter C: Geranylgeraniol - a new potential therapeutic approach to bisphosphonate associated osteonecrosis of the jaw. Oral Oncol 2011;47:195-201. 